\title{
Availability and accessibility of diabetes clinics on Trinidad: An analysis using proximity tools in a GIS environment
}

\author{
Patricia Boda \\ Department of Geosciences, Middle Tennessee State University, Murfreesboro, USA; pat.boda@mtsu.edu
}

Received 16 August 2013; revised 25 September 2013; accepted 8 October 2013

Copyright (c) 2013 Patricia Boda. This is an open access article distributed under the Creative Commons Attribution License, which permits unrestricted use, distribution, and reproduction in any medium, provided the original work is properly cited.

\begin{abstract}
Non-communicable diseases (NCDs), account for a growing number of deaths worldwide. The English-speaking Caribbean has the highest per capita burden of NCDs in the region of the Americas [1]. This paper presents an overview of availability and accessibility based on clinic hours and physician fulltime equivalents (FTE) on the island of Trinidad devoted to diabetes and wound care. The project integrates a Geographic Information System (GIS) with epidemiologic and bio-statistical data to provide a necessary spatial analysis not otherwise possible. It examines the island's ability to effectively deliver treatment to residents with diabetes by providing a geographic perspective to data published on the internet by the Trinidad-Tobago Ministry of Health and the Central Statistical Office. Results indicate a significant regional variability in both numbers of physicians and office hours devoted to diabetes treatment.
\end{abstract}

Keywords: Access; Health Care; Caribbean; Trinidad; Diabetes

\section{INTRODUCTION}

Non-communicable diseases (NCDs) are now the leading causes of deaths worldwide. In fact, heart disease, cancer, chronic respiratory diseases and diabetes account for $63 \%$ of all deaths [2]. Although the perception is that NCDs primarily affect wealthy nations, nearly $80 \%$ of NCD deaths occur in low- and middle-income countries [1,2]. The English-speaking Caribbean has the highest per capita burden of chronic non-communicable diseases (CNCDs) in the region of the Americas [1]. Cardiovascular disease, cancer, diabetes, and chronic res- piratory disease account for $71 \%$ of all deaths in Latin America and the Caribbean in 2008 and that rate is expected to rise to $81 \%$ by 2030 [2]. For the most part, these countries have passed through the demographic and epidemiological transition which has resulted in rapidly aging populations who are more prone to chronic illness.

Research concerning health in the Caribbean is somewhat limited as it is often linked with Latin America [3-5]. A portion of the work that has been produced on NCDs in the Caribbean has called for increased awareness and prioritization of combatting the epidemic rise of NCDs in the region [6,7] and strategies to be incorporated into public policy [8]. A fair volume of research has been based on surveys of self-reported prevalence of noncommunicable or chronic diseases [9-12]. These studies examined indicators affecting negative health status such as rural residence, age, gender and level of education, and have been conducted in various countries. A key factor affecting health status is the ability for a patient to visit a health care facility. The more often a patient receives an examination, the better health is believed to be. However, in many Caribbean countries, it has been documented that patients are often dissatisfied with treatment and are less likely to see a provider to manage their chronic illness [13]. In these studies, patients reported excessive wait times and too little time with providers.

The particular interest to this study is work regarding diabetes in the Caribbean, specifically research conducted on diabetes in Trinidad. Although much research is focused on epidemiological, diagnostic or treatment procedures [14-17], there are four primary areas of additional relevant research: 1) prevalence, 2) socioeconomic factors, 3) economic impacts, and 4) efficacy of treatments, in particular, treatment of foot wounds. Attempts to define the prevalence of diabetes on Trinidad and Tobago have produced interesting results. Early research of diabetes in Trinidad included a study by AriyanayagamBaksh in 1995, which reported that during a six-month 
period at Port of Spain General Hospital, 1447 patients with diabetes accounted for 1722 admissions. This accounted for $13.6 \%$ of hospital admissions and $23 \%$ of hospital bed occupancy in 1995, demonstrating the large burden of illness carries in Trinidad and Tobago [18]. In 1997, Guilliford found similar numbers of admission due to diabetes during another six-month period [19]. However, neither of these studies included data on the number of new cases nor repeated patients since the Ministry of Health did not report that information.

More recent attempts to determine prevalence rates of diabetes on Trinidad produced varied results. Chadee et al. determined self-reported prevalence of diabetes in 2008-2009 to be $19.5 \%$ [12] while Nicholls stated the rate was closer to $11 \%$ in 2010 [20] and WHO reported the figure to be approximately $14 \%$ in 2011 [1]. Regardless of the exact number, diabetes is now the second leading cause of death and the leading cause of blindness in Trinidad and Tobago [20]. Recently released epidemiological information on diabetes in Trinidad and Tobago reveals that 1 in 4 hospital admissions is attributed to diabetes. There were 1000 new cases diagnosed in persons aged 20 years or older in 2007. Trinidad and Tobago had the highest per capita rate of diabetes in the Western Hemisphere and ranked 5th in the world in that category [20].

Socioeconomic studies have documented the differences between the two dominant ethnic groups and between wealthy and lower income groups in the country. Ariyanayagam-Baksh reported that hospital admission rates were $33 \%$ higher in the Indian origin population and $47 \%$ lower in those of mixed ethnicity than those of African ancestry, suggesting ethnic associations exist [18]. These differences are significant since approximately $45 \%$ of the population is of Indian ancestry and $45 \%$ is of African ancestry. Guilliford's study concluded that prevalence and morbidity from diabetes were significantly greater in groups with lower socioeconomic status and lower educational achievement [19]. This is significant because although Trinidad and Tobago is considered as a high income country by the World Bank, much of the population is of relatively lower income.

The economic consequence of diabetes has an enormous impact on Trinidad-Tobago as well. Ariyanayagam-Baksh estimated that the annual cost of admissions with diabetes was conservatively estimated at TT\$ 10.66 million in 1995 [18]. More recently, the cost has been estimated at \$49,335,000 (TT\$296,010,000) as reported by Nicholls. However, Nicholls pointed out that the $\$ 49,335,000$ likely represented only direct costs. If indirect costs, such as loss of earnings due to illness or premature death, disability payments, time lost from work, and so forth, are factored in, the economic debacle assumes even graver proportions with more negative im- pacts on GDP [20].

Effective treatment options are important aspects to manage chronic illness and several studies have been conducted on various elements of diabetes treatment in Trinidad and Tobago. Popularity and value of traditional medicines were examined by Mahabir and Guilliford 1997 [21], and more recently by Motilal and Maharaj in 2012, both reported inconclusive results [22]. While some patients experienced improvement with some treatments, others did not. With few exceptions, little attention has been paid to the importance of patient self-management strategies. Self-management practices of monitoring chronic illnesses are very effective in reducing the economic burden and reducing hospital loads $[23,24]$. Because one serious and common complication of diabetes is foot wound which often results in amputation, availability of effective wound treatments and foot clinics are important areas of concern $[25,26]$.

While there have been many important publications on diabetes in Trinidad, little if any attention has been given to the network of hospitals and providers available to treat the thousands of persons with diabetes in Trinidad and Tobago. A geographic or spatial approach is an essential component when attempting to reduce the number or treat populations with diabetes. Such an analysis of access to services has been conspicuously absent from published research. This study attempts to fill this void by examining the level of available diabetes care based on established health districts and amount of clinic hours devoted to the treatment of diabetes. It presents an overview of facility services on the island of Trinidad. Data were entered into ArcMap. Distances and populations to provider ratios were calculated. The process revealed that there were significant deficits in access to services locally, regionally among the four health districts, and nationally.

\section{DATA SOURCES AND METHODS}

Community shapefiles with 2000 populations, streets and community boundaries were provided by The University of the West Indies, St. Augustine. Community files for Tobago were not included and therefore Tobago is not represented in this study.

Data on public clinic locations, street name and community as well as diabetes specific clinic hours were accessed from the Ministry of Health (MOH) website. The Ministry also included a schedule of clinic times devoted to particular conditions such as pre-natal, ante-natal, chronic disease, diabetes and wound care. However, clinic schedules only included "morning session" or "afternoon session" without a specific listing of times. Therefore it was assumed the morning session was 4 hours and the afternoon was 4 hours in length.

Each clinic schedule was examined and clinic times devoted specifically to "wound care" and "diabetes 
clinic" were calculated according to the following standards:

If morning hours stated only wound care or diabetes clinic the entire 4 hour morning clinic was entered into the calculations for diabetes clinics;

If morning schedule indicated wound care or diabetes clinic but also displayed other clinics such as pre-natal, ante-natal, primary care, or any other clinic, the time devoted to diabetes and wound care was divided proportionally among the number of other clinic hours.

Clinic hours devoted to wound and diabetes care were calculated by clinic, by district and nationally.

Clinic locations, hours of diabetes treatment and community data were entered into ArcMAp 10.0 for analysis and were manually placed on the community maps according to the following method:

The community was located on the community shapefile map using "select by attribute" for the community name. Street names for the clinics were located by the same method, and the clinics were laced on the correct street, in the correct community by placing the clinic in the middle of the street.

Hours of diabetes and wound care clinics were added and divided by 40 hours to produce a full time equivalent (FTE) for the provider. It was not stated if the clinic services were provided by a physician or another trained professional such as nurse, so the assumption was made that care was provided by a single physician.

Proximity was determined by applying buffers and Theissen Polygons.

Six clinics were not entered because no street name was provided, no community name was provided, or there was no schedule of hours provided.

\section{AVAILABILITY AND ACCESSIBILITY TO DIABETES CLINICS}

In order to effectively reduce the burden of diabetes in Trinidad, there must be a threefold approach that includes surveillance, prevention, and intervention. Surveillance consists of monitoring exposures (risk factors), monitoring outcomes. Prevention includes addressing exposures (risk factors) and enlisting education. Intervention and treatment examines levels of availability by assessing health system capacity and o access to services.

Access can be difficult to define as it is a multi-dimensional concept that evaluates the ability of a population to use medical services [27]. Penchansky and Thomas identified five dimensions that identify specific barriers: availability, accessibility, accommodation, affordability, and acceptability. Availability defines numbers of providers such as physicians, dentists, nurses and other health care workers in relation to the demand for their services. It also includes numbers of hospital beds and services that facilities provide. Accessibility generally describes geographic accessibility and identifies the geographic barriers to receiving such services such as distance, transportation, and travel time to the facility. Accommodation refers to the degree that services meet the needs of patients and include hours of service, waiting times, appointments and scheduling. Affordability discusses the cost of services and acceptability describes how the provider interacts with the patient on a personal level. Acceptability includes potential barriers such as gender, ethnicity, language and sexual orientation but also encompasses patient satisfaction [28]. Each dimension can obstruct access by creating barriers that limit utilization of services. This study utilizes the Penchansky and Thomas definitions of "availability" and "accessibility".

\subsection{Provider Availability by Health District}

Define Availability defines numbers of providers in relation to the demand for their services and includes numbers of services that facilities provide. The map of Trinidad in Figure 1, displays community populations by health district. It also reveals that clinics are located fairly unevenly on the island and clinics with higher numbers of hours devoted to diabetes care are shown with larger circles. Several clinics had zero hours scheduled.

In this study, assessment of the number of providers was based on scheduled hours devoted to diabetes care or wound care. Clinic hours devoted to diabetes and wound care ranged from zero to twelve hours per week at the Cumuto Clinic This was the only clinic with twelve hours scheduled per week. The clinic is located in the Eastern Health District and is identified in Figure $\mathbf{1}$ by the yellow cross.

Calculations of the Full Time Equivalents (FTE) for the providers reveal significant differences among the four health districts. Of the 14 clinics in Northwest District only 3 clinics reported to have diabetes/wound care hours scheduled. The 3 clinics had a total of 13 hours per week scheduled. Two clinics had 4 hours per week and 1 clinic had 5 hours. The 13 hours per week calculates to be 0.325 FTE. In the North Central district 8 of the 10 clinics had diabetes care scheduled. Hours ranged from 2 to 8 hours per week and totaled 50 hours per week resulting in an FTE of 1.25. The Eastern district has 16 clinics, 11 of which scheduled hours for diabetes care. Hours ranged from 3 to 12, totaling 65 hours per week and an FTE of 1.625. The Southwest district has the highest number of clinics and the highest FTE. Only one of the 25 clinics in this district did not have scheduled hours for diabetes or wound care. Hours scheduled ranged from 2 to 8 and totaled 114 hours per week which is 2.85 FTE. The total clinic-based FTE for diabetes or wound care on Trinidad therefore is 6.05.

Assessment of the demand for services of clinic and 


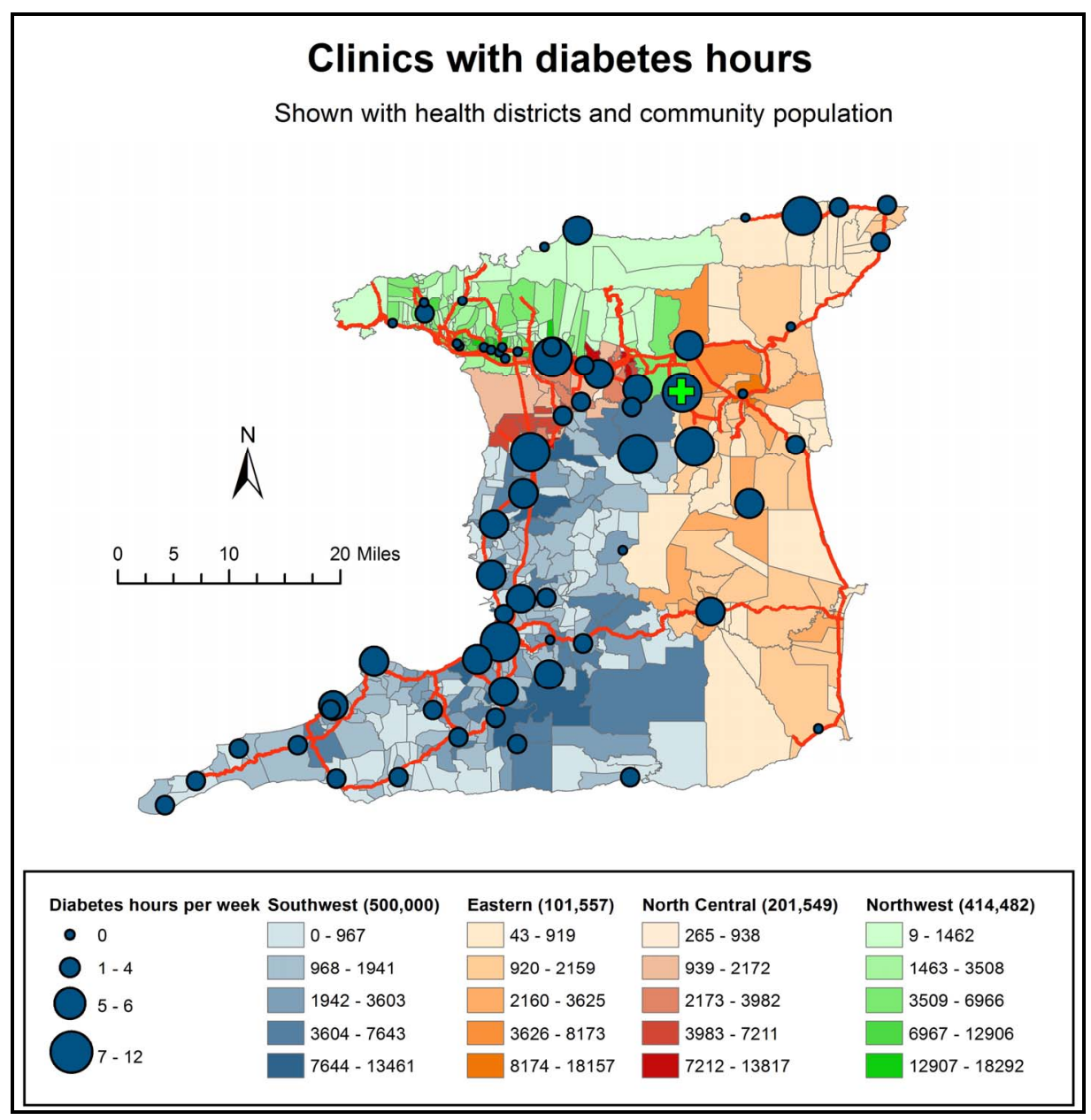

Figure 1. Clinic locations and number of hours devoted to diabetes care.

wound care scheduled hours was estimated by assuming approximately $15.25 \%$ of the population in each district has diabetes. That number represents the midpoint between the high estimate of $19.5 \%$ [12] and the lowest of $11 \%$ mentioned earlier [20]. With that assumption, there are approximately 76,250 people in the southwest district with diabetes, 15,487 in the eastern district, 30,736 in the north central, and 62,208 in the northwest. Using the $15.25 \%$ figure to estimate demand for diabetes services, there are a total of 185,681 persons on the island who have diabetes.

Population to provider ratios were estimated by calculating the estimated population with diabetes to FTE of physician clinic hours devoted to diabetes or wound care by district. Those ratios are 26,754:1 in the Southwest district, 9530:1 in the Eastern district, 128,991:1 in the North Central, and 191,409:1 in the Northwest. There are a total of 184,681 people with diabetes to 6.05 FTE clinic hours per week results in an island ratio of 30,525:1 (Table 1).

The highest population to diabetes provider ratio is in the North Central district. This is somewhat misleading however because there is a large, private medical facility, Eric Williams Medical Complex, located in the district. This analysis only includes public facilities. The Eastern district has the lowest ratio due to the large FTE at the Cumuto Clinic and the lower population.

\subsection{Geographic Accessibility}

Accessibility describes geographic accessibility and identifies the geographic barriers to receiving services such as distance, transportation, and travel time to the facility. As Figure 1 reveals, clinics are located throughout the island but are unevenly distributed. There is more clustering of facilities on the eastern or leeward side of the island where higher populations are, and more sparsely located in the southeastern quarter of the island. For the most part, it appears that the clinics are located near populations. However, when clinics with zero hours scheduled for diabetes care are eliminated as shown in Figure 2, there are several communities of the island lacking a clinic, several of which contain fairly substantial populations. 


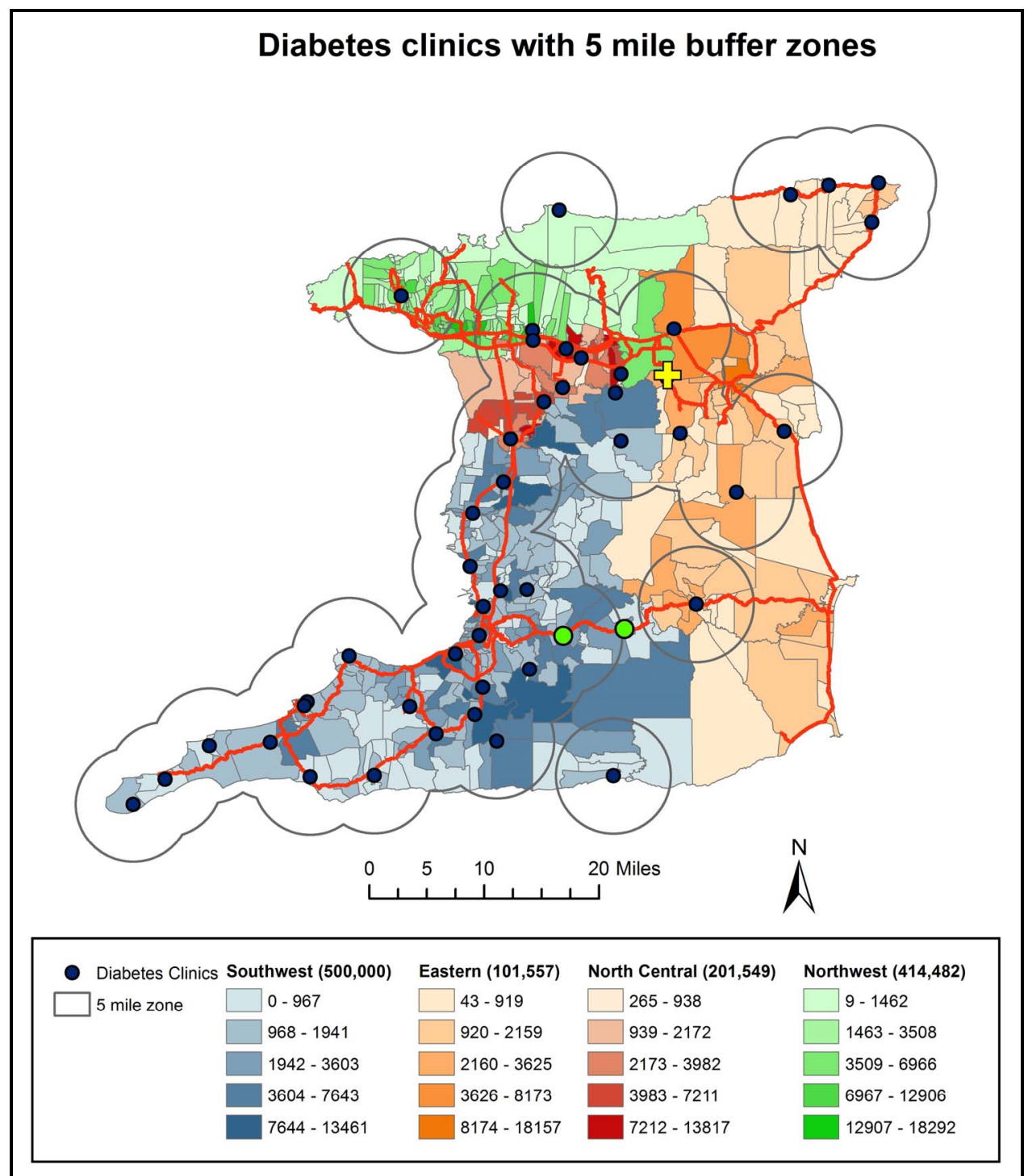

Figure 2. Clinics with diabetes care and 5 mile surrounding area.

Table 1. Estimated population to provider ratios (P:P) of health districts. Based on estimated persons with diabetes and FTE of diabetes clinics.

\begin{tabular}{|c|c|c|c|c|c|}
\hline & Southwest & Eastern & $\begin{array}{l}\text { North } \\
\text { Central }\end{array}$ & Northwest & $\begin{array}{c}\text { Trinidad } \\
\text { Total }\end{array}$ \\
\hline $\begin{array}{l}\text { Population } \\
2000\end{array}$ & 500,000 & 101,551 & 201,549 & 414,452 & $1,217,552$ \\
\hline $\begin{array}{c}\text { Diabetes } \\
\text { clinic FTE }\end{array}$ & 2.85 & 1.625 & 1.25 & 325 & 6.05 \\
\hline $\begin{array}{l}\text { Diabetes } \\
\text { Population }\end{array}$ & 76,250 & 15,487 & 30,736 & 62,208 & 1854,681 \\
\hline Diabetes P:P & $26,754: 1$ & 9,530:1 & 128,991:1 & 191,409:1 & $30,525: 1$ \\
\hline
\end{tabular}

Figure 2 also displays clinic locations with a 5 mile buffer around each clinic. While most of the island is included within the 5 mile zone, there are areas in the northern, central and eastern areas of the island that are not.

In addition, many of the areas within the 5 mile zone are a substantial distance from primary roads which are shown in red (Figure 2). These areas experience excessive drive times. Driving speed in Trinidad varies greatly. The central portion of the country is mountainous, creating both physical barriers to access as well as time. Changes in elevation and sharp turns on the roadways often reduce driving speed to 25 - 30 mile per hour or less. For example, Figure 2 displays a community on the edge of the 5 mile buffer from the clinic in Indian Walk. Both the clinic at Indian Walk and the community are symbolized with the green dots. By adding the lengths of each of the street segments, the actual driving distance on the primary road of Naparama Mayaro was calculated at more than 10 miles. It is likely that the driving time 
would be in excess of 20 minutes on a primary road. As indicated in Figure 2, there is a conspicuous lack of primary roads in central Trinidad.

Another method to determine accessibility is to examine the numbers of people served by a particular facility who drive excessive distances for health care. Assuming populations visit the provider nearest to them, a useful tool to measure FTE burden is to create "catchment" areas. That is, areas and the populations most likely to go to a certain facility for care. Theissen polygons create catchment areas where each clinic, in this case, is the center of the polygon. All points within that polygon are nearest to that clinic, and all other clinics therefore are further away. Figure $\mathbf{3}$ shows the Theissen polygon catchment areas for each clinic.

Ideally the polygons should show a somewhat equal burden on the diabetes clinic providers. That is, a higher
FTE should, in theory at least, have a larger catchment area in terms of square miles and in terms of the population which it serves in order to level the burden. This is not what is shown in Figure 3 however. Adding the segments of the primary road leading to the Rio Claro clinic, symbolized by the green dot, from the eastern edge of the island is more than 25 miles and would require nearly 45 minutes driving time.

Likewise, there are also inconsistencies in the number of persons served by the clinics. Although the polygons do not line up with the community boundaries, estimates of populations within the catchment polygons were established. Adding the population of the Rio Claro polygon and the Cumuto Clinic, it is clear the heavier burden is on Rio Claro with a population of 19,393 compared to Cumuto's population of 10,920.

Cumuto Clinic, which has the largest FTE of 0.3, has a

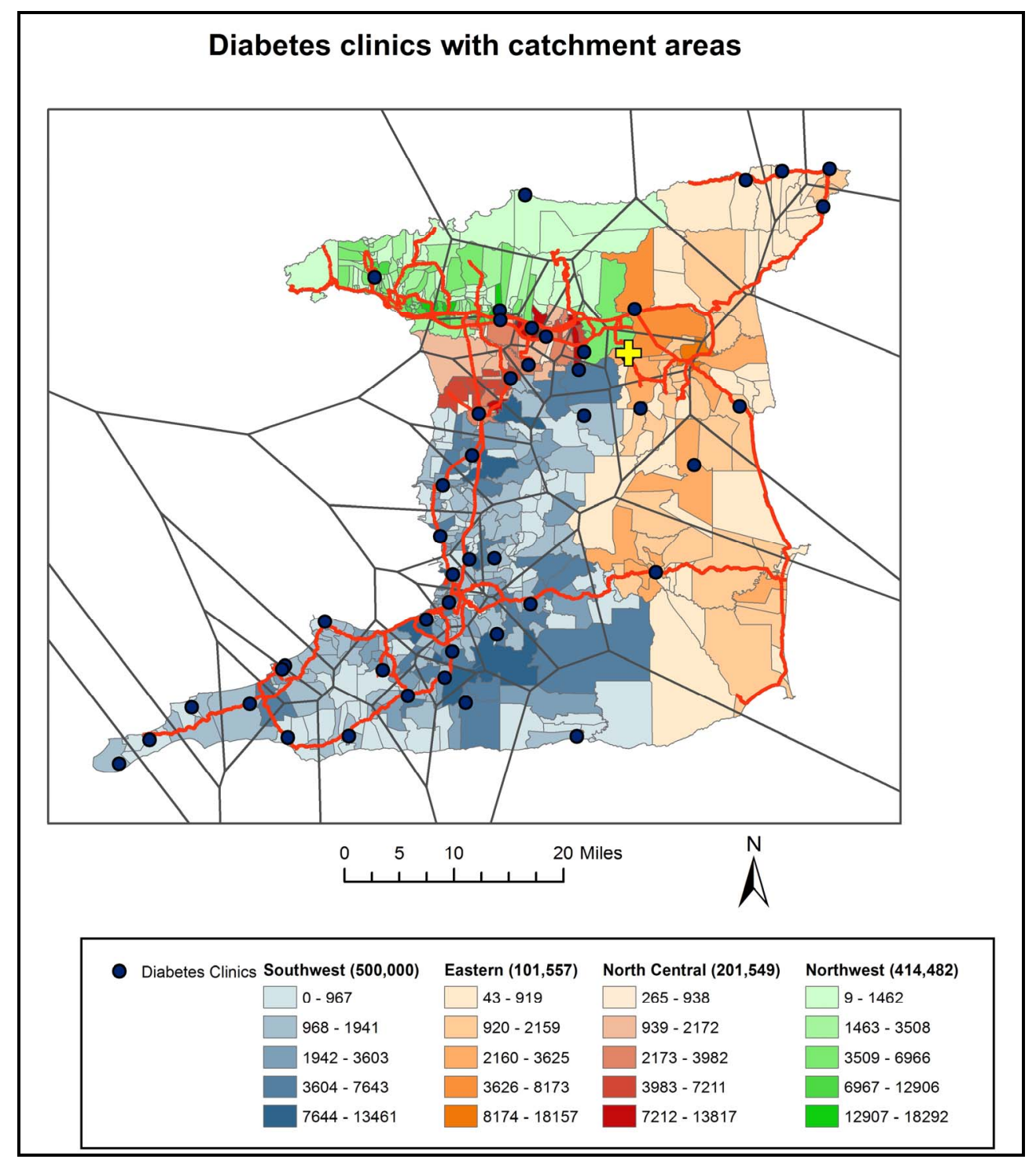

Figure 3. Diabetes clinics shown with catchment areas. 
significantly smaller area than Rio Claro, for example, which has an FTE of 0.1. The Rio Claro catchment area diabetes population is estimated at 4405 with an FTE of 0.1 . The population to provider ratio is $44,050: 1$.

According to the Bureau of Primary Health Care, the U.S. agency that determined which areas of the country are Health professional Shortage Areas or Medically Underserved, the acceptable ratio for populations to provider is 3500 persons for each provider and the acceptable driving time is 30 minutes [29].

\section{CONCLUSIONS}

This study presented a geographic overview of availability and accessibility to diabetes health services through public clinics. Trinidad faces a substantial challenge to reduce and treat the populations who have diabetes due to the small island size with limited resources. The four challenges represented in previous studies 1) high prevalence, 2) mixed socioeconomic factors, 3) substantial economic impacts, and 4) delivery of treatment, in particular, treatment of foot wounds, are great concerns today. The Ministry of Health has made strides to address the problem of treating existing cases. It is also attempting to reduce the number of new cases through educational programs targeted at youth [30]. However this assessment of the current status of availability of diabetes care on the islands reveals several concerns that need to be addressed.

The populations of the Southwest and North Central regions face enormous population to diabetes provider with ratios of more than 26,000:1 and 128,000:1 respectively. This results in a significant barrier to availability due to excessive wait times, limited time with the physician and ultimately little incentive to visit the provider. Availability of providers is essential to effectively manage diabetes.

The Eastern district has the lowest ratio due to the large FTE at the Cumuto Clinic and the lower population. It does however comprise the largest geographical area and distance becomes a barrier to geographic access as a result. Although there are several clinics in the district that schedule diabetes clinic hours, populations in the eastern district face substantial driving times to reach these clinics.

In addition, many populations in the central regions of the island face challenges of availability of providers and also geographic accessibility due to the mountainous terrain, lack of primary roads, and lack of clinics.

In summary, there is a significant lack of availability and accessibility to diabetes services in the public clinic system of Trinidad. Relocation of financial and personnel resources to areas severely underserved is desperately needed.

\section{LIMITATIONS}

Since the island of Tobago was not included in the shapefiles, this study represented only availability and accessibility on the island of Trinidad.

This analysis only includes public facilities with data published on the Ministry of Health website. Data were last updated in 2012. It is possible that more up-to-date information exists but has not yet been made available. The Ministry has been criticized by some people for the information that is made available is inaccurate and/or incomplete [20]. However when visiting the facilities in person to verify web data, I did not find that to be the case.

\section{FUNDING ACKNOWLEDGEMENTS}

Special acknowledge is due to the Faculty Research and Creativity Committee and the Geosciences Department at Middle Tennessee State University. This project would not have been possible without this substantial financial support received from the Middle Tennessee State University committee and the Department.

\section{REFERENCES}

[1] World Health Organization (WHO) (2013) Chronic illnesses.

http://www.who.int/topics/chronicdiseases/factsheets/en/i $\underline{\text { ndex.html }}$

[2] Population Reference Bureau (2013) Noncommunicable diseases and youth: A critical window of opportunity for Latin America/Caribbean. Policy Brief.

[3] Dachs, J., Norberto, W., Ferrer, M., Florez, C., Elisa, B., Aluisio, J.D., Narváez, R. and Valdivia, M. (2002) Inequalities in health in Latin America and the Caribbean: Descriptive and exploratory results for self-reported health problems and health care in twelve countries. $R e$ vista Panamericana de Salud Pública, 11, 335-355. http://www.scielosp.org/scielo.php?script=sci arttext\&pi $\mathrm{d}=$ S1020-49892002000500009\&lng=en\&tlng=en.10.1590/ $\underline{\text { S1020-49892002000500009 }}$

[4] Naomar, A.-F., Ichiro, K., Alberto, P.F. and Norberto, W.D.J. (2003) Research on health inequalities in Latin America and the Caribbean: Bibliometric analysis (19712000) and Descriptive Content Analysis (1971-1995). American Journal of Public Health, 93, 2037-2043. http://dx.doi.org/10.2105/AJPH.93.12.2037

[5] Montenegro, R.A. and Carolyn, S. (2006) Indigenous health in Latin America and the Caribbean. Lancet, 367, 18591869. http://dx.doi.org/10.1016/S0140-6736(06)68808-9

[6] Hospedales, C., James, S., Alafia, T., Cummings, R., Gollop, G. and Greene, E. (2011). Raising the priority of chronic noncommunicable diseases in the Caribbean. Revista Panamericana de Salud Pública, 30, 393-400.

[7] Perel, P., Casas, J.P., Ortiz, Z. and Miranda, J. (2006) Noncommunicable diseases and injuries in Latin America and the Caribbean: Time for action. PLOS Medicine, 3, e344. http://dx.doi.org/10.1371/journal.pmed.0030344 
[8] Ferguson, T.S., Tulloch-Reid, M.K., Cunningham-Myrie, C.A., Davidson-Sadler, T., Copeland, S. and Lewis-Fuller, (2011) Chronic disease in the Caribbean: Strategies to respond to the public health challenge in the region. What can we learn from Jamaica's experience? West Indian Medical Journal, 60, 397-411.

[9] Bourne, P.A. (2009) Socio-demographic determinants of health care-seeking behaviour, self-reported illness and self-evaluated health status in Jamaica. International Journal of Collaborative Research on Internal Medicine \& Public Health, 1, 101-130.

[10] Bourne, P.A. and Joan, R. (2009) Good health status of rural women in the reproductive ages. International Journal of Collaborative Research on Internal Medicine \& Public Health, 1, 132-155.

[11] Bourne, P.A. (2009) A theoretical framework of the good health status of Jamaicans: Using econometric analysis to model good health status over the life course. North American Journal of Medical Science, 1, 86-95.

[12] Chadee, D., Terrance, S., Lexley, M., Pinto, P., Mary, C., Rohan M., and Surujpal, T. (2013) Prevalence of selfreported diabetes, hypertension and heart disease in individuals seeking State funding in Trinidad and Tobago, West Indies. Journal of Epidemiology and Global Health, 3, 95-103. http://dx.doi.org/10.1016/j.jegh.2013.02.002

[13] Singh, H., Haqq, E.D. and Mustapha, N. (1999) Patients' perception and satisfaction with health care professionals at primary care facilities in Trinidad and Tobago. Bulletin-World Health.

[14] Pinto, P., Lexley, M., Terrance, S., Suruipal, T. and Shivananda N. (2013) Restrictive pulmonary deficit is associated with inflammation in sub-optimally controlled obese diabetes. Journal of Thoracic Disease, 5, 289-297.

[15] Nayak, S., Sateesh, S., Castay, G., Safia, C., Jacita, B., Cecile, M., David, D., Francesca, K. and Shaun, W. (2013) Evaluation of pulmonary dysfunction among persons with type 2 diabetes in Trinidad. International Journal of Research and Development in Pharmacy and Life Sciences. http://imsear.hellis.org/handle/123456789/146400

[16] Nayak, B.S., Ali, P., Seepersad, R., Cooke, N., Geawan, S., Brown, A., Ramdeen, A., Mahabir, L. and Lutchman, B. (2013) Type 2 diabetes, high triglycerides, LDL, are risk factors for cardiovascular disease in persons 45 years and older. International Journal of Research in Pharmaceutical and Biomedical Sciences, 4, 165-169.

[17] Nayak, B.S., Kameel, M., Shawn, S., Justin, S., Shalina, S., Crystal, S., Cadina, S., Victoria, S., Nirvani, S. and Munish, S. (2013) A comparison between HbA1c and fasting plasma glucose in the diagnosis of type 2 diabetes in Trinidad: A high prevalence setting. World Journal of Pharmacy and Pharmaceutical Sciences, 1, 1171-1180.

[18] Ariyanayagam-Baksh, S.M., Bickram, L., Picou, D. and Mahabir, D.:(1995) Counting the cost of diabetic hospital admissions from a multi-ethnic population in Trinidad. Diabetic Medicine, 12, 1077-1085. http://dx.doi.org/10.1111/j.1464-5491.1995.tb00424.x

[19] Gulliford, M.C., Ariyanayagam-Baksh, S.M., Bickram, L., Picou, D. and Mahabir, D. (1997) Social environment, morbidity and use of health care among people with diabetes mellitus in Trinidad. International Journal of Epidemioogy, 26, 620-627. http://dx.doi.org/10.1093/ije/26.3.620

[20] Nicholls, K. (2010) The diabetes epidemic in Trinidad \& Tobago: Attacking a burdensome disease with conventional weapons. White paper.

http://www.docs-archive.com/view/766d00e5c7c28db892 94aa2d77764114/THE-DIABETES-EPIDEMIC-IN-TRI NIDAD-\%26-TOBAGO.pdf

[21] Mahabir, D. and Guiliford, M.C. (1997) Use of medicinal plantgs for diabetes in Trinidad and Tobago. Revista Panamericana de Salud Publica, 1. http://dx.doi.org/10.1590/S1020-498919970003000002

[22] Motilal, S. and Rohan, G.M. (2013) Nutmeg extracts for painful diabetic neuropathy: A randomized, double-blind, controlled study. The Journal of Alternative and Complementary Medicine, 19, 347-352. http://dx.doi.org/10.1089/acm.2012.0016

[23] Gucciardi, E. and Souraya, S. (2013) A systematic literature review of diabetes self-management education features to improve diabetes education in women of Black African/Caribbean decent and Hispanic/Latin American ethnicity Patient Education and Counseling. Science Direct.

http://www.sciencedirect.com/science/artiucle/pii/S07383 9911300116X

[24] New and comprehensive study of diabetes care in Trinidad-Tobago released (2012)

http://www.hopkinsmedicine.org/news/media/releases/ne w_and_comprehensive_study_of_diabetes_care_in_trinid ad_and_tobago_released

[25] Carrington, S., Cohall, D.H., Gossell-Williams, M. and Lindo, J.F. (2012) The antimicrobial screening of a Barbadian medicinal plant with indications for use in the treatment of diabetic wound infections. West Indian Medical Journal.

http://caribbean.scielo.org/scielo.php?script=sci_arttext\& pid=S0043-31442012000900003\&lng=en\&nrm=iso

[26] Ferguson, T.S., Tulloch-Reid, M.K., Younger, N., WrightPascoe, R., Boyne, M., McFarland, S.R., Francis, D. and Wilks, R.J. (2012) Diabetic foot complications among patients attending a specialist diabetes clinic in Jamaica: Prevalence and associated factors. West Indian Medical Journal, 61.

[27] Lee, J., Wolch, J.R. and Walsh, J. (1998) Homeless health and service needs. In: Kearns, R.A. and Gesler, W., Eds., Putting Health into Place, Syracuse University Press, Syracuse.

[28] Penchansky, R. and Thomas, J.W. (1981) The concept of access: Definition and relationships to consumer satisfaction. Medical Care, 19, 127-140. http://dx.doi.org/10.1097/00005650-198102000-00001

[29] Bureau of Primary Health Care (BPHC) (2012) Published in The Federal Register, 77, Government Accounting Office, Washington DC.

[30] Trinidad and Tobago Ministry of Health website (2013) http://www.health.gov.tt/ 